\title{
Reduced performance difference between sexes in master mountain and city marathon running
}

This article was published in the following Dove Press journal:

International Journal of General Medicine

17 April 2013

Number of times this article has been viewed

\author{
Matthias A Zingg' \\ Beat Knechtle ${ }^{1,2}$ \\ Christoph Alexander Rüst' \\ Thomas Rosemann' \\ Romuald Lepers ${ }^{3}$ \\ 'Institute of General Practice and \\ Health Services Research, University \\ of Zurich, Zurich, Switzerland; \\ ${ }^{2}$ Gesundheitszentrum St Gallen, \\ St Gallen, Switzerland; ${ }^{3}$ INSERM \\ UI093, Faculty of Sport Sciences, \\ University of Burgundy, Dijon, France
}

Background: The performance in master marathoners has been investigated in flat city marathons but not in mountain marathons. This study examined changes in the sex differences in performance across time in female and male master runners competing in a mountain marathon compared to a flat city marathon.

Methods: The association between age and performance of finishers in the Jungfrau Marathon, Switzerland, with 1830 meter changes in altitude and a flat city marathon (Lausanne Marathon), Switzerland, were analyzed from 2000 to 2011.

Results: In both events, athletes in the 35-44 years age group showed the highest number of finishers. In the mountain marathon, the number of female master runners aged $>35$ years increased in contrast to female finishers aged $<35$ years, while the number of male finishers was unchanged in all age groups. In the city marathon, the number of female finishers was unchanged while the number of male finishers in the age groups for 25-34-year-olds and 35-44-year-olds decreased. In female marathoners, performance improved in athletes aged 35-44 and 55-64 years in the city marathon. Male marathoners improved race time in age group 45-54 years in both the city marathon and the mountain marathon. Female master runners reduced the sex difference in performance in the 45-54-year age group in both competitions and in the 35-44-year age group in the mountain marathon. The sex difference in performance decreased in the 35-44-year age group from $19.1 \% \pm 4.7 \%$ to $16.6 \% \pm 1.9 \%$ in the mountain marathon $\left(\mathrm{r}^{2}=0.39, P=0.03\right)$. In age groups $45-54$ years, the sex difference decreased from $23.4 \% \pm 1.9 \%$ to $15.9 \% \pm 6.1 \%$ in the mountain marathon $\left(\mathrm{r}^{2}=0.39, P<0.01\right)$ and from $34.7 \% \pm 4.6 \%$ to $11.8 \% \pm 6.2 \%$ in the city marathon $\left(r^{2}=0.39, P<0.01\right)$.

Conclusion: These findings suggest that female master runners aged 35-54 years reduced sex differences in their performance in both mountain and city marathon running.

Keywords: endurance, age, female, male

\section{Introduction}

Marathon running became a mass fitness phenomenon in the 1980s. ${ }^{1}$ Recent studies reported that master runners increased participation and improved performance in flat city marathon running, such as in the New York City Marathon., ${ }^{2,3}$ Master runners were defined as athletes typically older than 35 years of age and systematically training for and competing in organized forms of sport specifically designed for older adults. ${ }^{4}$ An age-related decrease in the number of finishers in master sports has been reported. ${ }^{5}$ However, the community of master runners is still growing quickly in marathons; ${ }^{3}$ conversely, the number of younger participants increased at a lower rate. ${ }^{2}$

Older master athletes are able to achieve exceptional performances. For example, the Canadian marathoner Ed Whitlock achieved, at the age of 80 years, a marathon race 
time of 3 hours, 15 minutes, and 54 seconds at the Toronto marathon held in 2011. ${ }^{6}$ In 2009, an 86-year-old man became a double champion in the European championship for road running. He won the $10 \mathrm{~km}$ road run with a time of 58 minutes and 1 second, setting a new European record for men aged 85 years and older. Two days later, he became a European champion in the same age group for the half-marathon, with a time of 2 hours and 17 minutes. $^{7}$

Several studies investigated participation and performance trends in master ultramarathoners where participation increased and performance improved. ${ }^{8,9}$ In marathon running, a few studies focused on the number of finishers and the performance in master marathoners competing in flat city marathons. ${ }^{2,3,10}$ The number of finishers in master runners increased at a higher rate than the number of younger marathoners, ${ }^{3}$ and their performances improved over time. ${ }^{2,3}$ Lepers and Cattagni ${ }^{3}$ showed an increase in performance for men older than 64 years and for women older than 44 years, competing between 1980 and 2009 in the New York City Marathon. Participation and performance trends for master runners in a city marathon, such as the New York City Marathon, have been investigated, ${ }^{2,3}$ but are not known for master runners competing in a mountain marathon. Apart from city marathon running, ${ }^{11}$ mountain marathon running is increasing in popularity. ${ }^{12}$

We intended to investigate whether the number and the performance of master runners would be similar in a mountain marathon when compared to a flat city marathon. Because of the selection bias (ie, starting places not being freely available for everyone in some of the major marathons, such as the New York City Marathon), we intended to compare a mountain marathon (Jungfrau Marathon) with a flat city marathon (Lausanne Marathon) with no limitation on the number of starters, and which were held in the same country (Switzerland) between 2000 and 2011, regarding changes in participation and performance trends in master runners. We hypothesized for both races that: (1) the number of master runners would increase; and (2) the performance of master runners would improve over the years.

\section{Methods}

Race times and ages of all finishers in the Jungfrau Marathon and the Lausanne Marathon between 2000 and 2011 were analyzed. The data were obtained from the race websites of the Jungfrau Marathon and the Lausanne Marathon. ${ }^{13,14}$ The Jungfrau Marathon was selected as the mountain marathon since this race was held in 2007 and 2012 as the official World Championship in mountain running. The study was approved by the Institutional Review Board of St Gallen, Switzerland, with a waiver of the requirement for informed consent, given that the study involved the analysis of publicly available data.

\section{Races}

The Jungfrau Marathon in Switzerland was established in 1993 and is one of the most popular mountain marathons in the world. ${ }^{13}$ The race is held annually with the start in Interlaken (565 meters (m) above sea level) and the finish at the Kleine Scheidegg (2095 $\mathrm{m}$ above sea level). It covers an overall ascent of $1830 \mathrm{~m}$ and an overall descent of $305 \mathrm{~m}$. The first quarter of the race is mostly flat and in the first half of the race the athletes had no more ascent than $300 \mathrm{~m}$ in the half-marathon distance (Figure 1). The Lausanne Marathon was established in 1992 and is the second most important Swiss city marathon following the Zürich Marathon. ${ }^{14}$ The race is held annually in autumn in Lausanne on the border of Lake Léman with 36 m of altitude change (Figure 1).

\section{Data analyses}

Data from 43,636 runners (including 7567 [17.3\%] women and 36,069 [82.7\%] men) who finished the Jungfrau Marathon between 2000 and 2011, and 20,464 runners (including 3104 [15.2\%] women and 17,360 [84.8\%] men) who finished the Lausanne Marathon between 2000 and 2011 were available. To analyze the performance in age groups, all athletes were divided in 10-year age groups: 15-24 years, 25-34 years, 35-44 years, 45-54 years, 55-64 years, 65-74 years, and 75-84 years. To calculate the performance ratio and sex differences from each age group, the annual top ten women and men were determined. Only those age groups with at least ten finishers in both sexes in at least eleven out of the twelve analyzed years were included. Due to the low number of finishers per age group, only athletes in the 25-34-year and 55-64-year age groups could be included in the data analysis. The performance ratio for both sexes and the sex differences in performance were calculated per age group and year, and these were subsequently analyzed regarding their change over time. The performance ratio was calculated using the equation:

(Running time of the overall top ten athletes)/(Running time of the top ten athletes in the respective

$$
\text { age group) } \times 100
$$

The performance ratio expresses the performance of the top ten athletes of an age group as a percentage of the performance of the overall top ten athletes and is a good indicator 


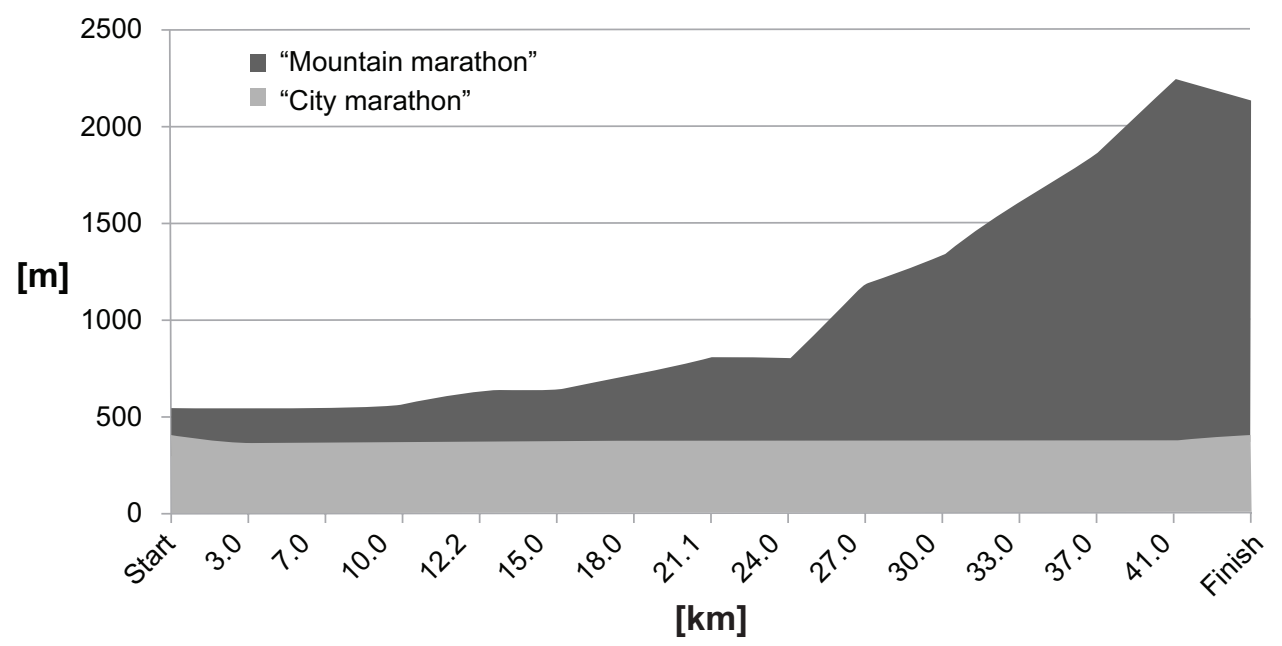

Figure I Course profiles of the Lausanne Marathon and Jungfrau Marathon.

Notes: Lausanne Marathon, shown as "city marathon," is in light gray. Jungfrau Marathon, shown as "mountain marathon," is in dark gray.

Abbreviations: $\mathrm{m}$, meter; $\mathrm{km}$, kilometer.

of the age-related decline in performance. ${ }^{3}$ The sex difference in performance was calculated using the equation:

([Running time in women] - [Running time in men])/

(Running time in men) $\times 100$

where the sex difference was calculated for every pairing of equally placed athletes (eg, between female and male first place, between female and male second place, and so on) before calculating the mean value and standard deviation of all the pairings. To facilitate reading, all sex differences were transformed into absolute values before analyzing.

\section{Statistical analysis}

To increase the reliability of the data analyses, each set of data was tested for normal distribution as well as for the homogeneity of variances in advance of the statistical analyses. Normal distribution was tested using the D'Agostino-Pearson omnibus normality test, and the homogeneity of variances was tested using Levene's test. To find significant changes in the development of a variable across years, linear regression was used. To find significant differences between two groups in case of normal distributed data, a Student's $t$-test was used with Welch's correction in case of significant different variances between the two compared groups. In case of not normal distributed data, the Mann-Whitney test was used. Statistical analyses were performed using the IBM Statistical Package for the Social Sciences version 19 (SPSS; IBM Corporation, Armonk, NY, USA) and GraphPad Prism Version 5 (GraphPad Software Inc, La Jolla, CA, USA). Significance was accepted at $P<0.05$ (two-sided for $t$-tests). Data in the text are given as mean \pm standard deviation.

\section{Results \\ Participation trends}

The number of finishers in the mountain marathon remained unchanged over the 12-year period (Figure 2A), whereas the number of finishers in the city marathon decreased (Figure 2B). In the mountain marathon, the number of women accounted for $17.3 \%$ of the total field, while they accounted for $15.2 \%$ in the city marathon. There was a significant increase in the number of female finishers in the Jungfrau Marathon (Figure 2A), but there was a decrease in the Lausanne Marathon (Figure 2B). The number of male finishers showed no change in the Jungfrau Marathon compared to a decrease in the Lausanne Marathon.

In both events, athletes in the 35-44 age group showed the highest number of finishers for both women and men (Figure 3). In the mountain marathon, the number of female master runners aged $>34$ years increased in contrast to female finishers aged $<35$ years (Figure 4A), while the number of male finishers was constant in all age groups (Figure 4B). In the city marathon, the number of female finishers was constant while the number of male finishers in the age groups of 25-34 and 35-44 years decreased.

\section{Performance trends}

For the top ten women and the top ten men in the Jungfrau Marathon (the mountain marathon), the overall running speed remained stable. In the Lausanne Marathon (the city marathon), the overall top ten women maintained their running speed. However, the overall top ten men became significantly slower as their running time increased by $8 \%$, from 139.8 minutes \pm 2.4 minutes (2000) to 151.1 minutes \pm 6.4 minutes (2011). 

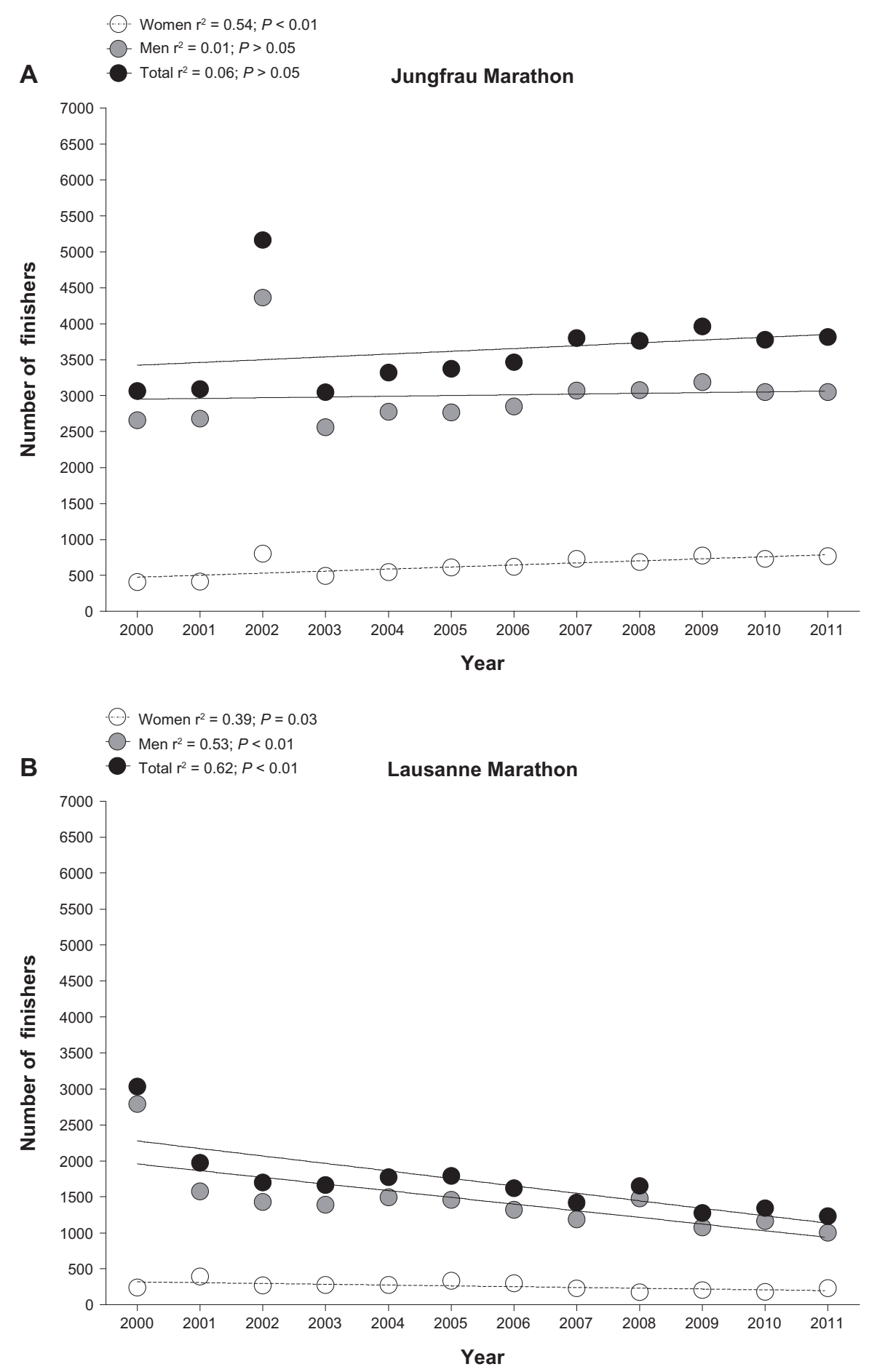

Figure 2 Number of female and male finishers in the Jungfrau Marathon and in the Lausanne Marathon. (A) Jungfrau Marathon results are depicted; (B) Lausanne Marathon results are depicted.

Figure 5 presents the changes in performance ratio for age group runners. In female marathoners, performance improved in athletes aged 35-44 years and 55-64 years in the city marathon (Lausanne Marathon). Male marathoners' race times improved in the 45-54-year age group in both the city marathon (Lausanne Marathon) and in the mountain marathon (Jungfrau Marathon). The analysis of the interaction between the type of competition and age group showed a significant interaction for women $(\mathrm{F}=5.7$; $P<0.0001)$, where the type of competition accounted for $35.3 \%(\mathrm{~F}=1232.5, P<0.0001)$ and age group accounted for $58.4 \%(\mathrm{~F}=224.9, P<0.0001)$ of the total variance. 

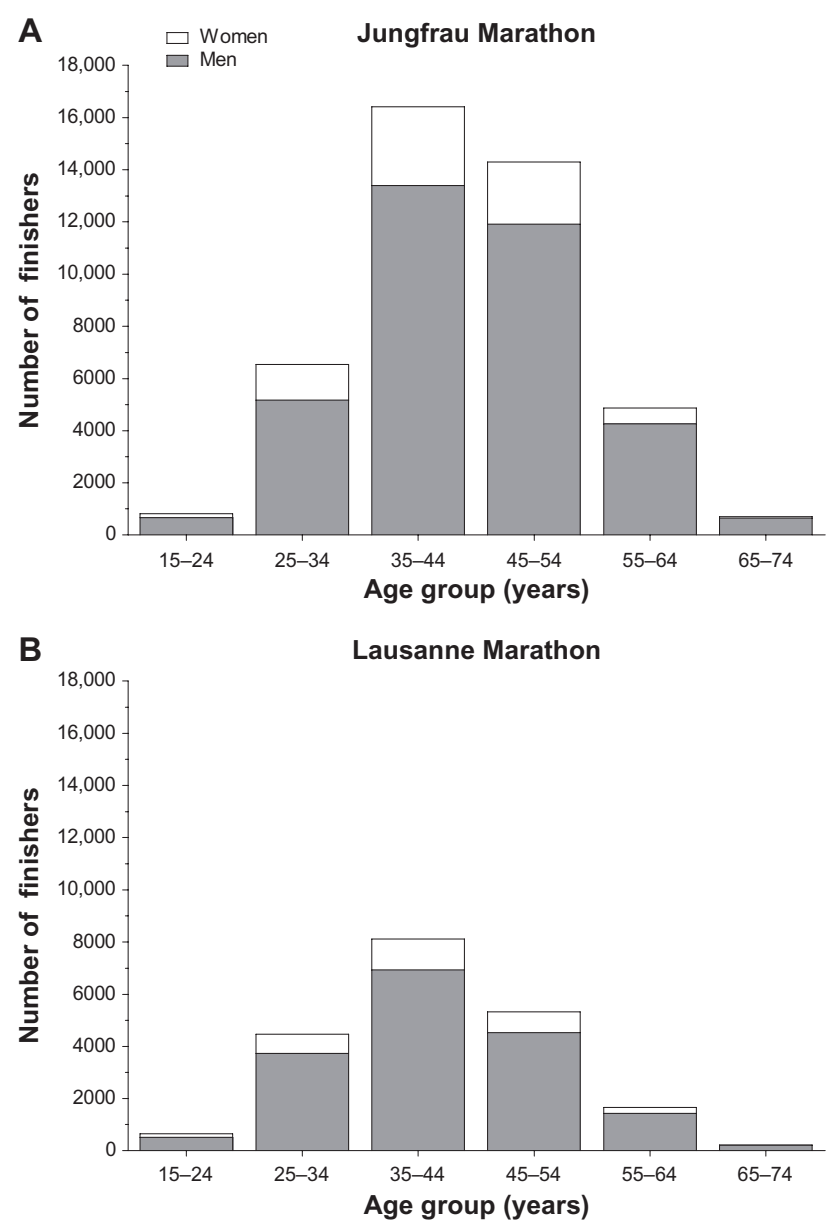

Figure 3 Number of female and male athletes per age group in the Jungfrau Marathon and in the Lausanne Marathon. (A) Jungfrau Marathon results are depicted; (B) Lausanne Marathon results are depicted.

For men, the type of competition and age group showed a significant interaction $(\mathrm{F}=9.3 ; P<0.0001)$, where the type of competition accounted for $52.4 \%(\mathrm{~F}=2028.7, P<0.0001)$ and age group for $41.2 \%(\mathrm{~F}=178.4, P<0.0001)$ of the total variance.

Figure 6 presents the changes in sex difference over time. Female runners reduced sex differences in performance in the 45-54-year age group in both competitions and in the 35-44-year age group in the mountain marathon (Jungfrau Marathon). In the mountain marathon (Jungfrau Marathon), the sex difference in the performance of the 45-54-year age group decreased from $23.4 \% \pm 1.9 \%$ (2000) to $15.9 \% \pm 6.1 \%$ (2011) in the mountain marathon and from $34.7 \% \pm 4.6 \%$ to $11.8 \% \pm 6.2 \%$ in the city marathon (Lausanne Marathon). In the mountain marathon, the sex difference of the $35-44$-year age group decreased from $19.1 \% \pm 4.7 \%$ (2000) to $16.6 \% \pm 1.9 \%$ (2011). The interaction analysis between the type of competition and age group on running speed showed significant interaction in terms of sex differences $(F=8.64$;
$P<0.0001$ ), where the type of competition and age group accounted for $71.8 \%$ of the total variance, and age group alone accounted for $71.7 \%(\mathrm{~F}=72.90 ; P<0.0001)$ of the total variance. The type of competition accounted for less than $0.01 \%$ of the total variance $(\mathrm{F}=0.02 ; P=0.90)$ and was insignificant.

\section{Discussion}

This study intended to compare participation and performance trends in runners of various age groups competing in a mountain marathon and a flat city marathon in the same country where the race director set no limit in the number of starters (in contrast to other marathons where the field is limited). We hypothesized for both races that: (1) the number of master runners would increase; and (2) the performance of master runners would improve over the years.

In the mountain marathon, the number of female finishers increased in every age group of master runners; the number of male finishers, however, remained constant. Eichenberger et $\mathrm{a}^{15}$ reported similar findings for mountain ultramarathoners, showing that the number of female finishers increased from 2000 to 2011 in the Swiss Alpine Marathon, whereas the number of male finishers remained unchanged. Only the number of master runners increased while the number of younger finishers (ie, $<35$ years old) remained constant. However, in the city marathon, the number of younger finishers (ie, $<45$ years old) decreased while the number of older male finishers was constant. A possible explanation might be that since the beginning of the Lausanne Marathon in 1992, an abundance of newer and larger city marathons has been offered in Switzerland, including the Zürich Marathon and others that have taken place abroad; therefore, runners now have a wider spectrum of competitions to choose from. ${ }^{11}$

Considering the performance of athletes based on age group, an important finding was that there was an increase in the performance ratio for female master runners aged 35-44 years and 55-64 years in the city marathon and for male master runners aged $45-54$ years in both the city and the mountain marathons. Marathoners in younger age groups, however, showed no improvements in performance in either marathon. Therefore, it seemed that female athletes in the mountain marathon reached their peak running speed and their performance may not improve anymore in the near future. Conversely, in the city marathon, women improved in the 35-44 and 55-64 age groups. Jokl et $\mathrm{al}^{2}$ reported an improvement in running speed for master runners at a faster rate than younger athletes in the New York City Marathon 

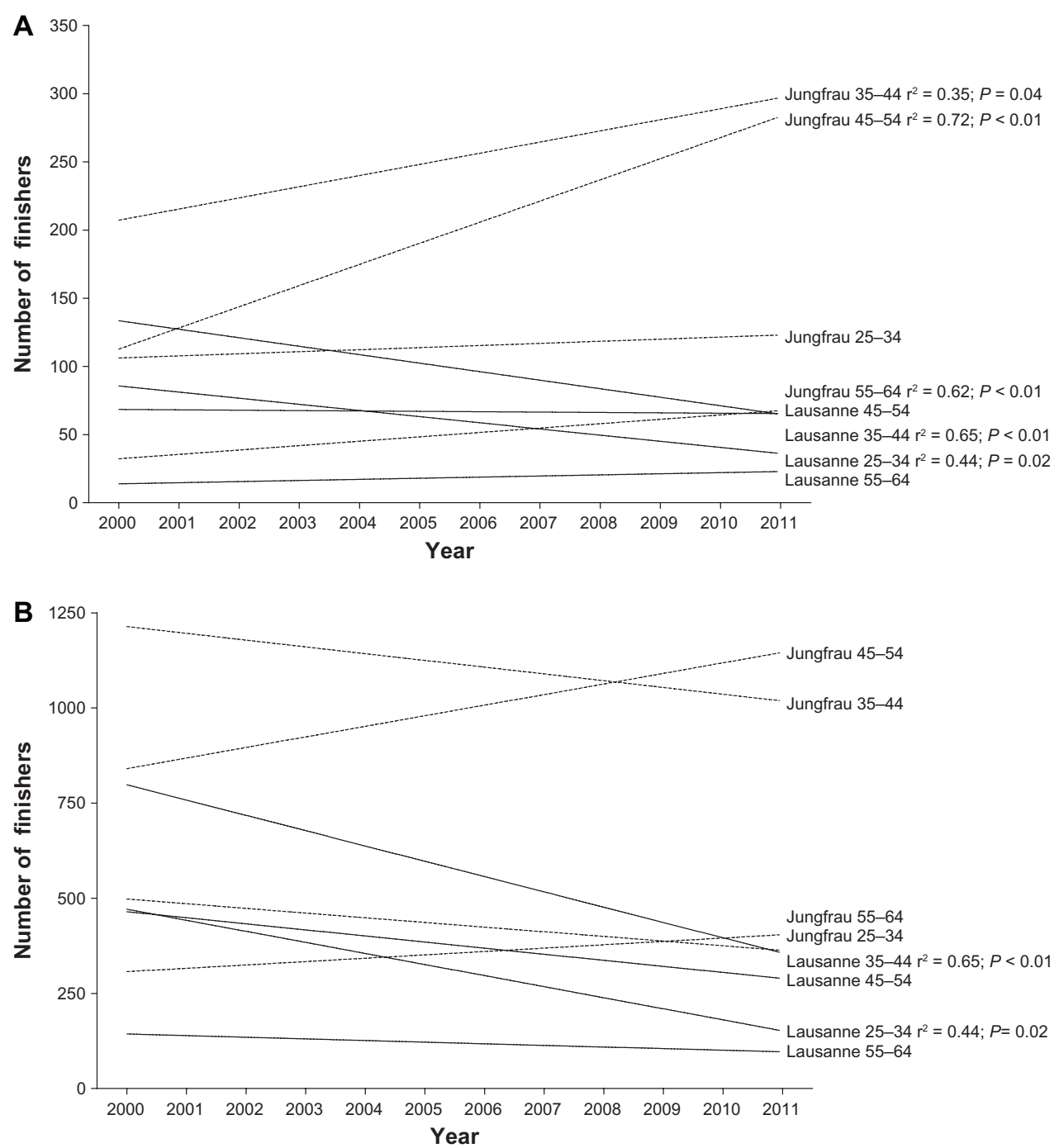

Figure 4 Number of finishers in the different age groups for women and men. (A) Women; (B) men.

Note: $r_{2}$ and $P$-values are indicated in the case of a significant change in sex difference over time.

from 1983-1999, which is consistent with our findings in the city marathon for men.

A possible explanation for the improvement of male master runners in the city marathon might be that the top ten men became significantly slower over the years. Therefore, even maintenance of running speed in master runners might have resulted in a relative improvement among the top ten runners in their respective marathon years. The finding that female master runners exhibited improved performances in city marathon running was consistent with the findings of Lepers and Cattagni, ${ }^{3}$ who reported a significant increase in running speed in women older than 45 years. While men between 45 and 54 years of age could improve their running speed in both a mountain and a city marathon, age-matched women could not. Women were able to improve race times in the city marathon in age groups 35-44 years and 55-64 years.
Women seemed to have reached their peak running speed in mountain marathon running, but this was increasingly true for the younger (ie, <44 years old) runners than for older runners. In the mountain marathon, the sex difference in the of 25-29-year age group was $15.4 \% \pm 1.7 \%$, while the difference in the 60-64-year age group was $20.4 \% \pm 2.1 \%$, which was consistent with the findings in the study by Hunter and Stevens, ${ }^{16}$ where the authors noted that the sex differences of running speed increased with advancing age in the New York City Marathon.

No changes in sex difference for running times were found between the top ten women and the top ten men in both races. Nevertheless, significant changes in the sex differences in running times in male athletes in the 45-54-year age group were found for both races. Additionally, the sex difference decreased in the 35-44-year age group in runners from the 

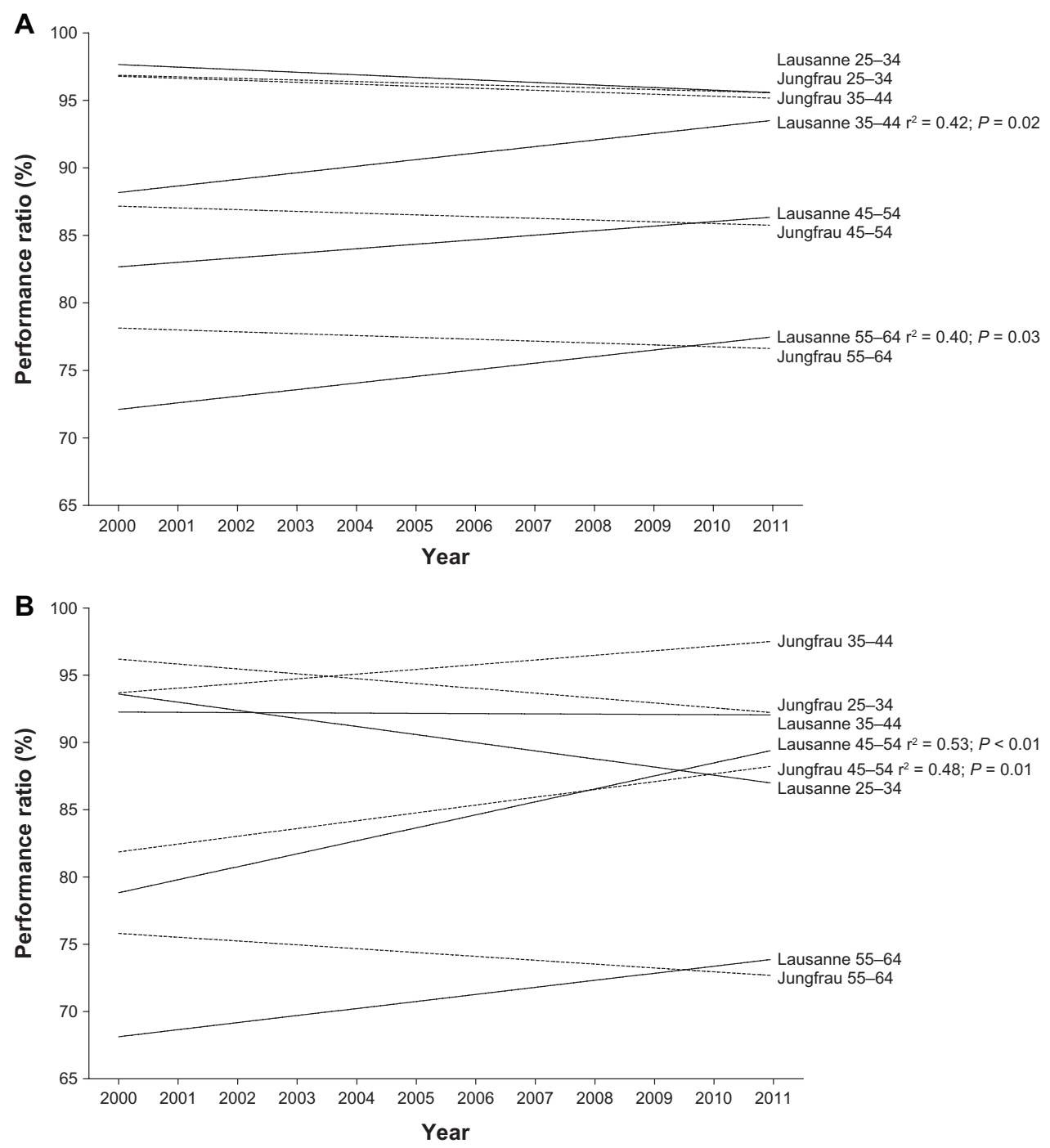

Figure 5 Changes in the performance ratio per age group per sex across the years. (A) Women; (B) Men.

Notes: Performance ratio is expressed as the percentage of performances of the overall top ten athletes in their respective marathon years. $r^{2}$ and $P$-values are indicated in the case of a significant change in performance ratio over time.

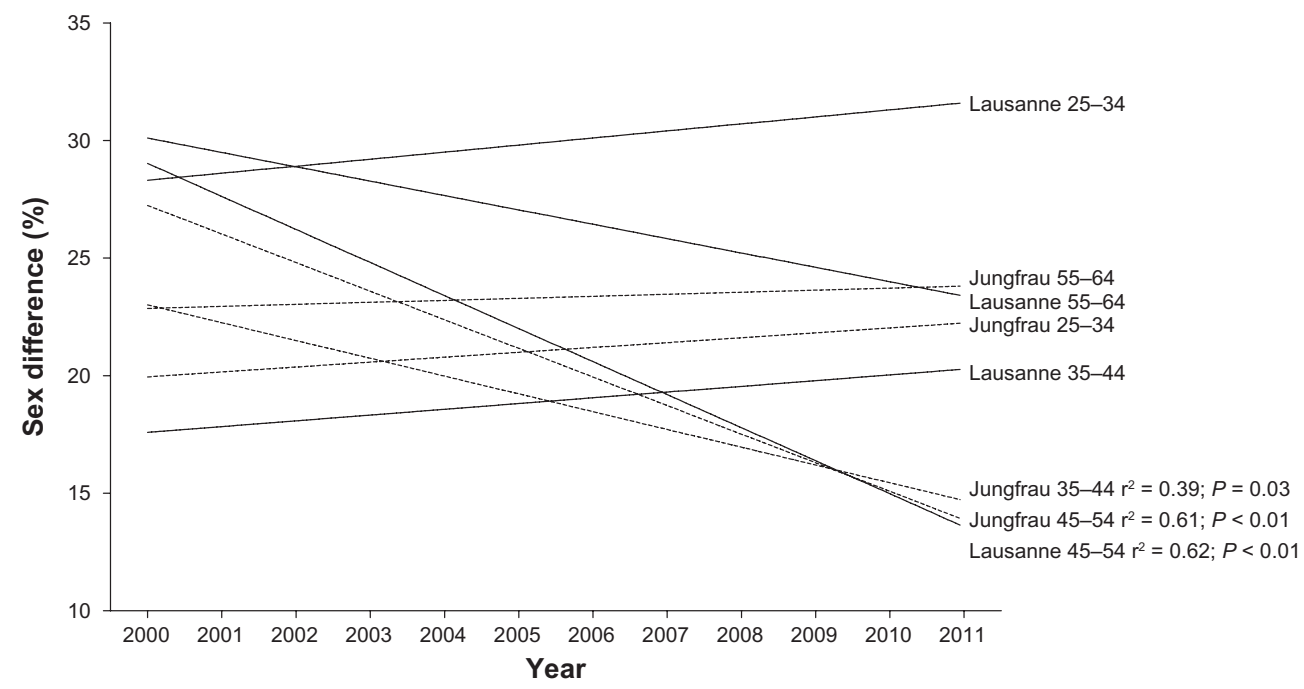

Figure 6 Changes in sex difference in running performance per age group across the years.

Note: $r^{2}$ and $P$-values are indicated in the case of a significant change in sex difference over time. 
mountain marathon. These findings suggest that female master runners older than 35 years reduced the sex difference in performance observed in both mountain and city marathon running. Studies concerning the sex differences in running exist for elite athletes and for recreational runners. ${ }^{15,17-20}$ The sex difference in endurance performance (ie, running speed) was a frequently discussed topic, ${ }^{21,22}$ and it was found to be existent in different sports disciplines. ${ }^{23}$ Twenty years ago, Whipp and Ward ${ }^{22}$ hypothesized that women would achieve the performance of men depending upon the distance. Existing findings show that women are unlikely to be able to outrun men in the near future, as the average difference in running speed between men and women decreased for a long time but leveled in recent years. ${ }^{24}$ Cheuvront et $\mathrm{al}^{24}$ reported a sex difference of $8 \%-14 \%$ for running distances from $1500 \mathrm{~m}$ to $42 \mathrm{~km}$, whereas the sex difference in running speed was on average about $11 \%$ in other competitions. ${ }^{18,21}$ Lepers and Cattagni ${ }^{3}$ showed relatively stable sex differences in marathon running times across the different age groups for the last decade in the New York City Marathon.

Considering the sex difference in performance, the interaction between the type of competition and running time was insignificant, and the sex difference in running speed was therefore independent from the type of competition. The time difference between sexes was constant over the years, while the sex difference was smaller between the mountain marathon runners compared to the city marathon runners. The fastest female runner was about 16\% slower in the mountain marathon and approximately $18 \%$ slower in the city marathon compared to the top ten women in the mountain marathon, with approximately $19 \%$ difference in running speed and approximately $22 \%$ in the city marathon. Cheuvront et $\mathrm{al}^{24}$ similarly found that the sex difference in performance was constant but smaller at around 8\%-14\% in competitions ranging from $1500 \mathrm{~m}$ to the marathon distance. ${ }^{24}$ In longer distances, Coast et $\mathrm{al}^{25}$ reported a mean sex difference of $12.4 \%$ over distances ranging from $100 \mathrm{~m}$ to $200 \mathrm{~km}$. The difference in running speed between winners and the top ten runners can be partly explained by the lower number of female finishers and, therefore, the faster decline in performance in women.

We found a highly significant interaction between the type of competition and the age of the top ten runners. To the best of our knowledge, there was never a direct comparison between a mountain and city marathon in terms of running times and age. Nevertheless, other studies suggested that the type of competition and the age of the top ten runners were directly related. Eichenberger et $\mathrm{al}^{15}$ found that there was a mean age of approximately 35 years for the top ten runners over the time span of 14 years at the Swiss Alpine Marathon held in Davos, Switzerland. ${ }^{15}$ Conversely, in city marathon running, the average age of runners was reported to be at around 30 years for both women and men. ${ }^{18,26}$ Since these two types of competitions were not directly compared, our results cannot be definitively supported by these findings.

\section{Limitations and implications for future research}

This study is limited since variables such as physiological parameters, ${ }^{27}$ anthropometric characteristics, ${ }^{20,28,29}$ training characteristics, ${ }^{20,28,30,31}$ previous experience, ${ }^{32}$ nutrition, ${ }^{33}$ and weather were not considered. ${ }^{34}$ It would be of interest to compare the same women and men competing in both the city and the mountain marathon. Female marathoners with lower body mass and lower body mass index compared to male marathoners might hold an advantage and achieve relatively faster race times..$^{30,31}$

\section{Conclusion}

To summarize, the number of female master runners increased in the mountain marathon. The sex difference in performance decreased in the 35-44-year age group in the mountain marathon. In runners aged 45-54 years, the sex difference decreased in the mountain marathon and in the city marathon. These findings suggest that female master runners reduced the sex difference in performance in both mountain and city marathon running.

\section{Disclosure}

The authors report no conflicts of interest in this work.

\section{References}

1. Burfoot A. The history of the marathon: 1976-present. Sports Med. 2007;37(4-5):284-287.

2. Jokl P, Sethi PM, Cooper AJ. Master's performance in the New York City Marathon 1983-1999. Br J Sports Med. 2004;38(4):408-412.

3. Lepers R, Cattagni T. Do older athletes reach limits in their performance during marathon running? Age (Dordr). 2012;34(3):773-781.

4. Reaburn P, Dascombe B. Endurance performance in masters athletes. Eur Rev Aging Phys Act. 2008;5:31-42.

5. Wright VJ, Perricelli BC. Age-related rates of decline in performance among elite senior athletes. Am J Sports Med. 2008;36(3):443-450.

6. Lepers R, Stapley PJ, Cattagni T, Gremeaux V, Knechtle B. Limits in endurance performance of octogenarian athletes. J Appl Physiol. 2013; 114(6):829.

7. Knechtle B, Kohler G, Rosemann T. Study of a European male champion in 10-km road races in the age group $>85$ years. Proc (Bayl Univ Med Cent). 2010;23(3):259-260. 
8. Zingg M, Rüst CA, Rosemann T, Lepers R, Knechtle B. Master runners dominate the 24-hour ultramarathons worldwide - a retrospective data analysis from 1998 to 2011. Extreme Physiology and Medicine. In press.

9. Zingg M, Rüst CA, Knechtle B, Rosemann T, Lepers R. Analysis of participation and performance in age group athletes in ultramarathons of more than $200 \mathrm{~km}$ in length. Int J Gen Med. In press.

10. Leyk D, Erley O, Ridder D, et al. Age-related changes in marathon and half-marathon performances. Int J Sports Med. 2007;28(6):513-517.

11. Web Marketing Associates. live2run ${ }^{\mathrm{TM}}$ Marathon guide.com [homepage on the Internet]. New York, NY: Web Marketing Associates; 2013. Available from: http://www.marathonguide.com. Accessed April 14, 2012.

12. Rose D. Your backcountry trail running/ultra running resource [homepage on the Internet]. Park City, UT: BackcountryRunner.com; 2012. Available from: http://www.backcountryrunner.com. Accessed March 27, 2012.

13. Verein Jungfrau Marathon. Verein Jungfrau-Marathon [homepage on the Internet]. Interlaken, Switzerland: Verein Jungfrau Marathon; 2013. Available from: http://www.jungfrau-marathon.ch. Accessed April 14, 2012.

14. Lausanne Marathon. Lausanne Marathon [homepage on the Internet]. Lausanne, Switzerland: Lausanne Marathon; 2013. Available from: http://www.lausanne-marathon.com. Accessed April 14, 2012.

15. Eichenberger E, Knechtle B, Rüst CA, Rosemann T, Lepers R. Age and sex interactions in mountain ultramarathon running - the Swiss Alpine Marathon. Open Access Journal of Sports Medicine. 2012;3:73-80.

16. Hunter SK, Stevens AA. Sex differences in marathon running with advanced age: physiology or participation? Med Sci Sports Exerc. 2013;45(1):148-156.

17. Baker AB, Tang YQ. Aging performance for masters records in athletics, swimming, rowing, cycling, triathlon, and weightlifting. Exp Aging Res. 2010;36(4):453-477.

18. Hunter SK, Stevens AA, Magennis K, Skelton KW, Fauth M. Is there a sex difference in the age of elite marathon runners? Med Sci Sports Exerc. 2011;43(4):656-664.

19. Pate RR, O'Neill JR. American women in the marathon. Sports Med. 2007;37(4-5):294-298.

20. Knechtle B, Knechtle P, Barandun U, Rosemann T, Lepers R. Predictor variables for half marathon race time in recreational female runners. Clinics (Sao Paulo). 2011;66(2):287-291.

21. Thibault V, Guillaume M, Berthelot G, et al. Women and men in sport performance: the gender gap has not evolved since 1983. J Sports Sci Med. 2010;9:214-223.
22. Whipp BJ, Ward SA. Will women soon outrun men? Nature. 1992 355(6355):25

23. Medic N, Young BW, Starkes JL, Weir PL, Grove JR. Gender, age, and sport differences in relative age effects among US Masters swimming and track and field athletes. $J$ Sports Sci. 2009;27(14):1535-1544.

24. Cheuvront SN, Carter R, Deruisseau KC, Moffatt RJ. Running performance differences between men and women: an update. Sports Med. 2005;35(12):1017-1024.

25. Coast JR, Blevins JS, Wilson BA. Do gender differences in running performance disappear with distance? Can J Appl Physiol. 2004; 29(2):139-145.

26. Schulz R, Curnow C. Peak performance and age among superathletes: track and field, swimming, baseball, tennis, and golf. J Gerontol. 1988;43(5):P113-P120.

27. Billat VL, Demarle A, Slawinski J, Paiva M, Koralsztein JP. Physical and training characteristics of top-class marathon runners. Med Sci Sports Exerc. 2001;33(12):2089-2097.

28. Knechtle B, Knechtle P, Rosemann T. Race performance in male mountain ultramarathoners: anthropometry or training? Percept Mot Skills. 2010;110(3 Pt 1):721-735.

29. Knechtle B, Rüst CA, Knechtle P, Rosemann T. Does muscle mass affect running performance in male long-distance master runners? Asian $J$ Sports Med. 2012;3(4):247-256.

30. Schmid W, Knechtle B, Knechtle P, et al. Predictor variables for marathon race time in recreational female runners. Asian J Sports Med. 2012;3(2):90-98.

31. Barandun U, Knechtle B, Knechtle P, et al. Running speed during training and percent body fat predict race time in recreational male marathoners. Open Access Journal of Sports Medicine. 2012;2012(3):51-58.

32. Rüst CA, Knechtle B, Knechtle P, Barandun U, Lepers R, Rosemann T. Predictor variables for a half marathon race time in recreational male runners. Open Access J Sports Med. 2011;2011(2):113-119.

33. Rodriguez NR, Di Marco NM, Langley S; for American Dietetic Association, Dietitians of Canada, American College of Sports Medicine. American College of Sports Medicine position stand. Nutrition and athletic performance. Med Sci Sports Exerc. 2009;41(3):709-731.

34. Ely MR, Cheuvront SN, Roberts WO, Montain SJ. Impact of weather on marathon-running performance. Med Sci Sports Exerc. 2007; 39(3):487-493.
International Journal of General Medicine

\section{Publish your work in this journal}

The International Journal of General Medicine is an international, peer-reviewed open-access journal that focuses on general and internal medicine, pathogenesis, epidemiology, diagnosis, monitoring and treatment protocols. The journal is characterized by the rapid reporting of reviews, original research and clinical studies across all disease areas.

\section{Dovepress}

A key focus is the elucidation of disease processes and management protocols resulting in improved outcomes for the patient. The manuscript management system is completely online and includes a very quick and fair peer-review system. Visit http://www.dovepress.com/ testimonials.php to read real quotes from published authors. 